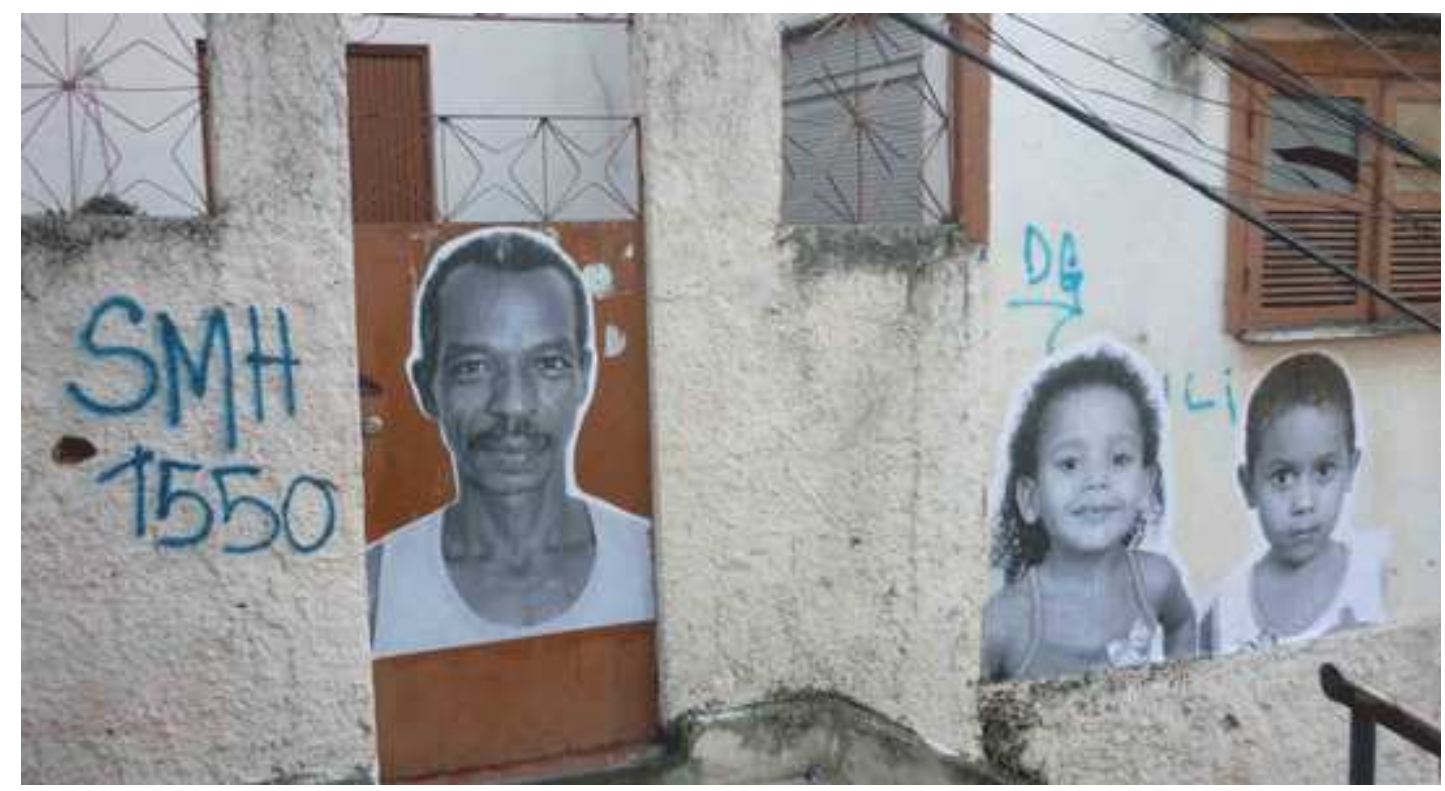

\title{
E quando a pichação é da prefeitura? Pichar, proscrever, dessubjetivizar
}

And what about graffiti done By municipality administration? Spraying, proscribing, de-subjectivating

\section{Resumo}

Neste trabalho focalizamos dois gestos de interpretação que, inscritos em moradias populares, materializam dois diferentes processos de significação: a escrita de uma sigla em casas de uma favela e fotografias de moradores nas paredes externas às casas marcadas com a referida sigla. Dois gestos antagônicos que decorrem de um programa da prefeitura da Cidade do Rio de Janeiro, "Morar Carioca", programa articulado ao um projeto governamental, o Projeto Porto Maravilha.

Palavras-chave: relato, fotorreportagem, periferia, análise do discurso

\begin{abstract}
In this paper, we have focused on two interpretation gestures. They are both inscribed in popular housing buildings and they materialize two different meaning-construction processes: the writing of an acronym on houses in slums and dwellers' photos on the walls outside the acronym-marked houses. Those two antagonistic gestures derive from a program named "Morar Carioca", created by Rio de Janeiro Municipality Government. That program is articulated to a governmental project known as Projeto Porto Maravilha
\end{abstract}

Keywords: reporting, photojournalism, periphery, discourse analysis

\footnotetext{
* Professora do Departamento de Ciências da Linguagem da UFF, pesquisadora do programa de Pósgraduação em Estudos da Linguagem, bolsista 1C de Produtividade em Pesquisa pelo CNPq, coordenadora, com Vanise Medeiros, do Laboratório Arquivos do Sujeito da UFF.

** Professora do Departamento de Ciências da Linguagem da UFF, pesquisadora do programa de Pósgraduação em Estudos da Linguagem, bolsista 2 de Produtividade em Pesquisa pelo CNPq, Jovem Cientista do Estado pela FAPERJ, coordenadora, com Bethania Mariani, do Laboratório Arquivos do Sujeito da UFF. Este artigo conta com o apoio do CNPq (Edital MCTI / CNPq / MEC / CAPES no. 07 / 2011).
} 
Não habitamos porque construímos. Ao contrário. Construímos e chegamos a construir à medida que habitamos, ou seja, à medida que somos como aqueles que habitam.

Mas em que consiste o vigor essencial do habitar?

Heidegger

1.

Um sintoma social urbano, que é o das formas de resistência à modificação do espaço ocupado por comunidades, é aqui objeto de reflexão.

No Morro da Providência, sem muito aviso prévio por parte da prefeitura, e durante a ausência dos moradores, que em sua maioria havia saído para trabalhar, algumas casas foram pichadas com a sigla "SMH" - Secretaria Municipal de Habitação -, para serem derrubadas em função de projeto de reurbanização proposto pela prefeitura para o corpo da cidade. Tomamos aqui a cidade como um corpo e as pichações da prefeitura como aquilo que será cortado do corpo da cidade desfazendo laços daquele espaço urbano. Contrapondo-se às pichações da prefeitura, reproduções muito ampliadas de fotos dos moradores - fotos dos rostos e de corpo inteiro - foram feitas por um fotógrafo, morador da favela e líder comunitário, como resposta às marcações, como forma de resistência à derrubada das casas.

Nesse trabalho propomos uma discussão sobre as formas de escrita do social no corpo da cidade, seja a da escrita institucional da prefeitura que, através de pichações, normatiza, restringe e ordena sem perguntar, proscrevendo os moradores de seu lugar de origem; seja a de outra forma de escrita, feita a partir de imagens de pessoas que, com sua corporalidade, inscrevem um discurso de outra ordem, portando as marcas dos que resistem fora da normatividade urbana.

Falamos do lugar teórico da Análise do Discurso, o que significa dizer que tais sites e blogs foram lidos como discurso urbano, ou seja, materializam com palavras e imagens um sintoma social contemporâneo que é o das formas de ocupação do espaço nas cidades e as disputas aí envolvidas entre o poder público e moradores de áreas urbanas a serem modificadas em função de algum tipo de projeto do estado (governo e prefeitura).

Focalizamos, então, dois gestos de interpretação que, inscritos em moradias populares materializam dois diferentes processos de significação: a inscrição de uma sigla em casas de uma favela e de fotografias de moradores nas paredes externas às casas marcadas com a referida sigla. Dois gestos que decorrem de um programa da prefeitura da Cidade do Rio de Janeiro, "Morar Carioca", programa articulado ao projeto governamental, Projeto Porto Maravilha. Este último se apresenta com o 
objetivo de recuperação da zona portuária do Rio de Janeiro, articula-se ao "Morar Carioca" e atinge uma favela, Morro da Providência ${ }^{1}$, no centro da cidade do Rio.

Nossa análise incidirá sobre estes dois gestos de interpretação inscritos nas paredes das casas, duas marcações: da sigla "SMH" e das fotos dos moradores. Duas materialidades distintas, duas posições em confronto: uma que porta uma impessoalidade, uma vontade de política pública e uma ordem jurídica sem margem para questionamentos; outra que confronta o impessoal da política urbana ao explicitar a subjetivação, ou seja, que dando cara e corpo aos moradores, reivindica uma ética. A análise dessas duas materialidades será entremeada por análises dos relatos dos moradores do Morro da Providência cujas casas foram marcadas.

2.

Um arquivo de imagens está em construção no Laboratório Arquivos do Sujeito (www.uff.br/LAS), visando à captura na mídia de fotografias da violência (seja social, urbana, policial, escolar, territorial, entre outras) na sociedade e de formas de resistência a essas violências. Para analisar o arquivo fotográfico que vem sendo construído pelo LAS, um desafio transdisciplinar se impõe, o qual conjuga a materialidade da letra ao lado da materialidade da fotografia como formas de construção de uma narratividade que se apaga como tal. Um dos tópicos de discussão para o LAS é a compreensão de que a fotorreportagem joga com a ilusão de estar colada a um referente, produzindo o efeito testemunha, de "prova irrefutável" para o relato em questão.

Em trabalho anterior, (MARIANI \& MEDEIROS, 2011), mostramos como a fotorreportagem acena para o relato, para uma narratividade, rompendo com a objetividade com que se supõe o discurso jornalístico e produz efeitos de sentido variados. Nesse artigo, trabalhamos com a imagem de uma adolescente que se deixa fotografar sorrindo e armada com uma pistola em uma das ruas da favela da Rocinha, no Rio de Janeiro. Discutimos essa fotografia colocando-a em confronto com outras imagens e textos jornalísticos publicados na revista Veja e no Jornal do Brasil.

No processo de construção do arquivo sobre situações de confronto social e

\footnotetext{
${ }^{1}$ Há uma extensa literatura que aponta esta favela como a primeira da cidade do Rio de Janeiro (Davis, 2006, e Campos, 2007, Risério, 2012, para citar algumas fontes). Em dois dos sites trabalhados http://www.cultureisyourweapon.com/2011/06/providencia-inside-out, em língua inglesa, e http://rioonwatch.org.br/?p=2808 -, também se encontra a história da formação da favela: abrigos provisórios por combatentes da guerra de Canudos (final do século XIX) à espera de moradia prometida pelo governo. Denominada incialmente "Morro da Favela", em função de uma planta lá existente conhecida como favela, passa a abrigar, posteriormente, escravos libertos que lá se juntaram aos moradores primeiros (http://rioonwatch.org.br/?p=2808).
} 
urbano, não consideramos apenas a mídia impressa, investigamos também a que circula nas redes internáuticas. Sites e blogs, embora não tenham assumidamente um caráter jornalístico, funcionam como tal na medida em que, além de colocar em circulação notícias sobre os antagonismos sociais e urbanos, atuam como porta-vozes de minorias que usualmente são 'invisíveis' na grande imprensa. Assim, para este artigo, elegemos como material a ser descrito e analisado, fotos e textos em sites e blogs que registram confrontos em torno da questão da moradia popular. São os seguintes sites e blogs:

http://apublica.org/2012/04/rj-casas-vao-cair/providaancia/;

http://rioonwatch.org.br/?p=2808;

http://www.anf.org.br/2011/07/projeto-sem-teto-carioca-relato-de-umamoradora-do-morro-da-providencia/;

http://www.cultureisyourweapon.com/2011/06/providencia-inside-out/; http://raquelrolnik.wordpress.com/2011/05/23/intervencao-artistica-chamaatencao-para-remocoes-no-morro-da-providencia-no-rio-de-janeiro/;

http://saudosamalocamalocaquerida.blogspot.com.br/2012/04/rj-as-casas-vaocair.html.

Nos relatos, lemos que casas foram marcadas com a sigla "SMH" com tinta spray e sem esclarecimento ("encontrei uma marcação em minha porta" / "marcou minha casa sem me informar o que isso significa"). Não se trata de uma sigla padronizada e impressa às casas; nas fotos nos sites $^{2}$, vemos que elas foram feitas à mão, algumas letras garrafais, outras menores; caligrafia irregular.

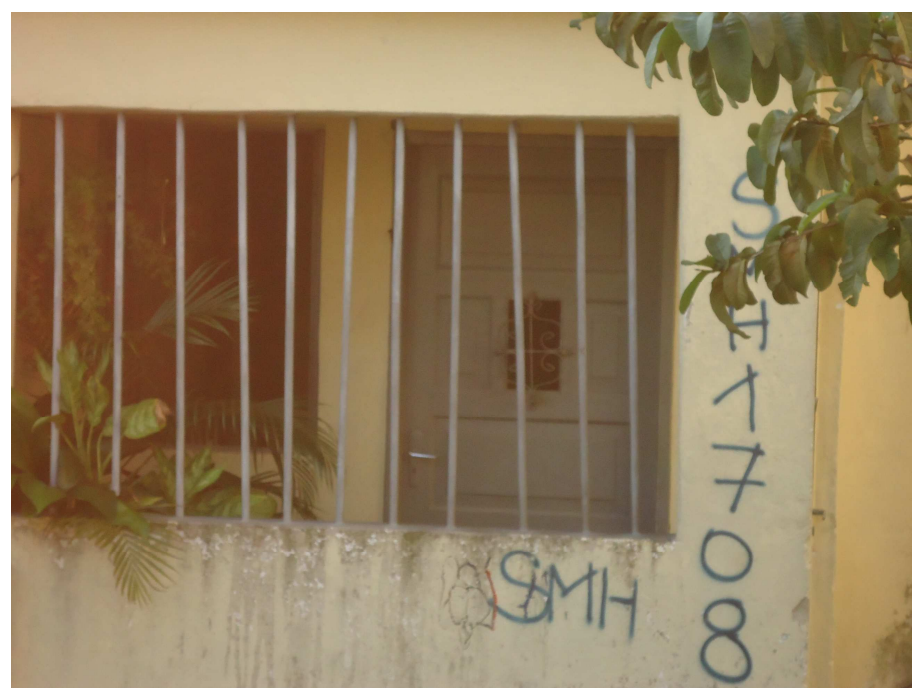

\footnotetext{
${ }^{2}$ Além das fotos dos sites e blogs, tivemos a oportunidade de subir ao Morro da Providência, ver as marcações e conversar com o fotógrafo, Maurício Hora, que fez as fotos dos moradores. As fotos de Maurício Hora encontram-se também na revista Multidutes, $\mathrm{n}^{\circ}$. 49, 2012, p. 114-131, Inculte Revue. Revista impressa e em site: www.revuemultitude.net.
} 


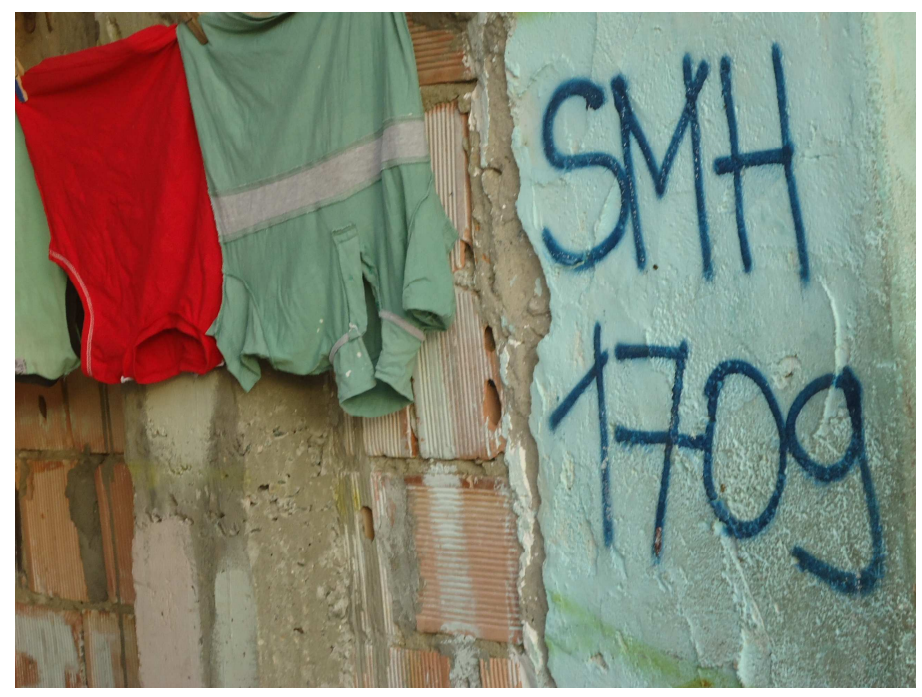

Fotos: Viviane Gueller ${ }^{3}$

Em que consiste uma sigla? No Hoauiss (2009), encontramos que são letras de diversas palavras, letras sem formar palavras, abreviação, redução, acrógrafo, rubrica, marca. Em Cabré (apud HENRIQUES, 2007, p. 137), a sigla resulta em palavras por um "processo de truncação", isto é, palavras formadas de letras iniciais de palavras. Se no Houaiss ela é marca, em Cabré já a temos como palavra. Pensando-a discursivamente, diremos que a sigla consiste em uma dobra sobre a palavra cujo funcionamento complexo - de "truncação da palavra" que se transforma em letra, de letra que se transforma em sílaba e de sílaba que se transforma em palavra outra opacifica a palavra que nela, sigla, resultou. Sua força reside no seu funcionamento: apagamento e esquecimento da palavra outra ao mesmo tempo em que se instaura como palavra outra. Diferentemente de outros processos de formação de palavras, em que se acresce ou se subtrai afixo e com eles se deslocam sentidos, na sigla a palavra se apaga para virar letra que vira palavra outra, passível de derivações como qualquer palavra. Palavra sobre palavra cuja ilusão reside na redução à letra. A sigla vale pelas palavras outras e, nesse processo de substituição da palavra pela sigla, inscrevem-se duas posições discursivas: a de quem produz, gesto sobre o dizer; e a do outro, instado a ler a sigla em sua opacidade e a dar sentidos àquilo que a redução apaga. Sem esquecer que, se uma sigla é uma marca, em nossa sociedade uma sigla é também um logotipo e uma assinatura (rubrica). Personaliza um produto, uma empresa, um governo, uma instituição.

O que isso significa? A resposta nos sites e blogs é "Secretaria Municipal de Habitação", uma expressão que, em blogs de moradores, comparece com o equívoco

\footnotetext{
${ }^{3}$ Fotos gentilmente cedidas por Viviane Gueller, artista visual e jornalista, e-mail: vigueller@gmail.com
} 
"Secretário Municipal da Habitação" em lugar de "Secretaria Municipal da Habitação"; equívoco que retira o gesto do estado da impessoalidade ao dizer "secretário".

SMH, uma sigla pichada, ou seja, uma pichação-sigla-assinatura do Estado sobre a moradia popular: casa marcada para ser demolida. Uma sigla que possui a autoridade do estado sobre a moradia: marca que condena a casa e proscreve o morador.

Poderíamos propor, aqui, que, para os moradores do morro da Providência, essas siglas, enquanto marcas nas casas, em sua opacidade enigmática para a maioria dos moradores, funcionam com efeito de uma pichação. Pichação que os moradores sabem ter sido feita por um órgão público.

Do ponto de vista do poder instituído, compreende-se a pichação - "com seus estranhos sinais gráficos" (ORLANDI, 2004, p. 110) - como sujeira nas paredes dos muros, dos monumentos e das casas, ou pode ser lida como marcas que delimitam territórios, que escrevem histórias de grupos socialmente discriminados ou que reivindicam um espaço de fala. Das letras inscritas nas pichações se compreende muito pouco, em função de sua indistinção gráfica. Porém, podemos nos perguntar: indistinção gráfica para quem? Tal indistinção gráfica, alerta Orlandi (idem), não é apartada da exclusão social e urbana de muitos dos pichadores e, nesse sentido, no gesto da pichação materializa-se um gesto de luta que torna visível o se significar ao mesmo tempo em que significa um modo singular de existência e de resistência. Resistência social e, por que não dizer, resistência frente aos processos que homogeneízam e indistinguem os sujeitos. Pichar - com símbolos e letras em sua maioria indiscerníveis tem esse aspecto de produzir uma singularidade, ou melhor, uma forma de subjetivação de referências sobre o mundo e, também, de delimitação de territórios e pertencimento a lugares ou grupos.

No caso do Morro da Providência, a pichação é uma sigla do Estado. É uma pichação não passível de criminalização; ao contrário, tem a força da lei que indica casa a ser desocupada. Não se trata de gesto de resistência por parte daquele que picha. Nessas pichações inscreve-se a contradição do Estado: pune aquele que picha muros e monumentos por serem púbicos, ao mesmo tempo em que picha moradias privadas. Se privilégio advém de lei (legis) do privado (privi) (ELIA, 2010), a pichação pelo Estado retira o privilégio do privado.

\footnotetext{
${ }^{4}$ Em alguns sites e blogs, comparece 'Secretário Municipal da Habitação" em lugar de "Secretaria Municipal da Habitação". Para nós, analistas de discurso, este equívoco, falha no dizer, produz sentidos: retira o gesto do estado da impessoalidade ao dizer "secretário".
} 
O conjunto de siglas "SMH" vem acompanhadas de uma numeração, estava inscrito nas casas de modo bastante legível e discernível, mas isso não era garantia de sua interpretabilidade a priori da parte dos moradores. No entanto, uma vez que ganha em compreensão, a sigla SMH ao mesmo tempo em que delimita um grupo - as casas que devem ser demolidas em nome da revitalização do espaço urbano -, proscreve esse mesmo grupo ao marcar suas casas para excluí-los do espaço que habitam. Em outras palavras, a sigla-pichação se impõe como história que passará a ser contada em função da reforma urbana e, simultaneamente, determina o apagamento do que é singular, da memória histórica que os moradores representam.

3.

O corpo urbano é marcado por inscrições desde sempre. São marcas que delimitam espaços e produzem sentidos sobretudo para os que são letrados naquele "código" em uma determinada época histórica. O que não impede, contudo, que seja lido e significado pelo outro que não pertence àquele "código". O que estamos salientando é que faz parte da cidade a marcação do espaço com escrita própria de um certo pertencimento. As marcações nas cidades são inscrições das alteridades no urbano. São marcações com valor de nomeações que escrevem e inscrevem, histórica e socialmente no urbano, processos de identificação, contra-identificação e desidentificação (PÊCHEUX, 1979 [1988)].

Assim, a disposição e o número de tijolos (ou ladrilhos) na fachada de uma casa em Paraty, por exemplo, era compreensível para membros da maçonaria. Ou ainda, o número de beirais em casas dos séculos XVIII e XIX, em Ouro Preto e Olinda, era indicativo do poder aquisitivo de seu dono. Antigas igrejas romanas, por sua vez, eram construídas e ostentavam as armas do papa eleito na ocasião, registrando em suas fachadas os movimentos da história do cristianismo. Entretanto, é importante dizer que essas variadas formas de escrita e inscrição não têm o mesmo valor e nem devem ser compreendidas da mesma forma.

Com a crescente urbanização, todo um aparato de painéis, outdoors e placas surge e é imposto pelo Estado conforme as cidades se ampliam e vão necessitando de regulamentações propostas por uns poucos, mas valendo e normatizando a vida de todos. Pichações e grafites, por sua vez, guardadas as diferenças entre ambos, e o alegado valor artístico atual conferido apenas ao segundo, são manifestações contemporâneas de desenhos, letras, siglas que colocam em circulação uma resistência e 
um enigma aos poderes que organizam os sentidos do urbano. Siglas enigmáticas, palavras e frases - moradores do Rio de Janeiro na faixa dos 50 a 60 anos devem se lembrar da frase "Celacanto provoca maremoto", pichada em muros da cidade no final dos anos 70, assim como pichações políticas durante a ditadura militar, e siglas, como CV (Comando Vermelho), ou outras, ainda -, mostram que o espaço arquitetônico urbano pode ser lido como um texto. Nossa proposta aqui é ler esse texto discursivamente, considerando a cidade como um corpo habitado, 'habitado', aqui, no sentido que lhe dá Heidegger: “(...) habitar é o traço fundamental do ser-homem”.

Minimamente, pode-se afirmar que as inscrições nas casas, que são nosso objeto de estudo, colocam em jogo relações de força antagônicas no que diz respeito ao espaço urbano da cidade do Rio de Janeiro. Pode-se filiar essas marcas, inscritas sem a autorização dos moradores, às marcas do "bota abaixo" da reforma Pereira Passos, ou, se recuarmos ainda mais no tempo, às marcas que apontavam quais moradores deveriam deixar suas casas para a coroa portuguesa que vinha para o Brasil em 1808.

Há uma escritura social inscrita no corpo urbano. Ou, dito de outra maneira, há inscrições no urbano que decorrem de uma escritura do social: seja de uma escrita institucional normativa, restritiva e ordenadora, seja de uma escrita que porta as marcas dos que resistem ou formam lugares sociais fora da normatividade urbana.

Se fazem parte da cidade mudanças, reformas, derrubadas e marcações delimitando espaços, nos relatos dos sites e dos blogs, duas memórias são retomadas para as marcações advindas pelo estado: uma que diz do Brasil ("D. João vai chegar e precisa de casas para sua corte"); outra que remete à condição dos judeus na Segunda Grande Guerra ("voltamos ao Nazismo, onde as casas dos judeus eram pintadas com suásticas"). Ambas recuperam as marcações que excluem: em um caso, um povo; em outro, aqueles que aqui habitavam e que tiveram de ceder suas casas à corte. Em um, o gesto totalitário do Nazismo; em outro, o gesto autoritário do Estado.

4.

Ao lado da opacidade visível da sigla - que se mostra e, ao mesmo tempo, que vela aquele que ali assina -, pintada em azul em tamanhos variados e à mão, outra materialidade a ladeia: a foto do morador. Fotos enormes expõem rostos em preto e branco $^{5}$ dos moradores - crianças, velhos, adultos - cujo suporte é a parede externa da

\footnotetext{
${ }^{5}$ Flusser (2011, pag. 60-61) nos lembra que as primeiras fotografias eram em preto e branco e que a cor longe de consistir numa captura "verdadeira" é uma vitória da química. Por exemplo, "o "verde do bosque fotografado é imagem do conceito 'verde', tal como elaborado por determinada teoria química. O
} 
casa, ocupada em sua quase totalidade. Não há intervenção de legenda, não há escritura em volta que as identifique, explique ou narrativize. Assim, as fotos propõem um enigma e uma abertura nas interpretações para aqueles que desconhecem a memória de sua inscrição nas paredes das casas. Mas também, ao mesmo tempo, postas em silêncio nas paredes, elas narrativizam pelo simples fato de estarem ali: produzem gritos de protesto e trazem para o exterior aqueles que ali habitam, aqueles que estão no interior dando-lhes visibilidade. Sua força é dar a conhecer aqueles que lá habitam no movimento inverso da sigla e do número que dessubjetiva. As fotos singularizam aqueles que lá habitam no movimento inverso da sigla que mortifica; em seu suporte parede-externa-da-casa produzem ainda outro efeito: se personalizam com os closes dos rostos, a ausência do nome mantém, contudo, o anonimato que protege. Não se trata um morador identificado, mas de qualquer um, integrante ou não daquela comunidade que poderia ocupar aquela posição social.

A sigla vem ao lado de um número (indicativo de quantas casas foram marcadas para serem derrubadas. Mais de mil). Com a foto, as casas se singularizam em relação à ordem e à ordenação imposta com os números que compõem a sigla pela prefeitura da cidade: número que identifica ao mesmo tempo que desubjetiva os moradores.

Um álbum de família é, seguindo Sontag (2004), uma crônica visual da família. Os rostos expostos nas fotos, colados nos muros das casas do Morro da Providência, funcionam, diremos, como a escrita de uma crônica social atravessada pela memória dos moradores tecendo o complexo laço entre o singular de um rosto familiar - morador de uma casa - e o social - morador de uma casa que será demolida.

Ainda conforme Sontag, “desde quando as câmeras foram inventadas, em 1839, a fotografia flertou com a morte" (2003, p. 24); isto é, desde o início a fotografia produziu imagens para a guerra, para o choque, para a morte. Horror, exaltação ou denúncia sempre fizeram parte de sua prática. Embora tal prática inscreva-se numa suposta perseguição de uma objetividade da realidade, sabemos que não são quaisquer corpos que são fotografados (eles têm nacionalidade e classe social, por exemplo) tampouco qualquer guerra ou qualquer horror. A foto enquadra, como lembra a autora, e, ao enquadrar, exclui, inclui, produz imagens, que se inscrevem em redes de memória. Do ponto de vista discursivo, diremos que as fotografias (se) inscrevem em redes de memória discursiva, em que o lembrar se faz na tensão com o esquecer. 
Com as fotos, os moradores se inscrevem no corpo da cidade ao mesmo tempo em que escrevem uma denúncia e produzem um movimento de resistência ${ }^{6}$ - no caso resistência à demolição das casas - que se faz pela intervenção artística. Fotos que escrevem imagens de rostos de cidadãos simples e comuns, despercebidos por serem cidadãos do nosso cotidiano, mas que, nelas, ganham contornos outros por serem objeto de intervenção artística. Expõem seu desamparo e sua fragilidade no corpo socialurbano; suas imagens promovem (ou podem promover) o efeito de solidariedade diante da perda da casa, de vergonha diante da impotência de sua condição social.

A concepção moderna de resistência, segundo Birman, em sentido amplo, é "uma força que se opõe a outra que ataca do exterior a um certo território" (2006, p. 323), ou seja, resistência é aí significada como reação. O que Birman irá destacar é que a oposição ação versus reação começa a se configurar nos tempos modernos - até a alta Idade Média a oposição à ação era paixão (adoecer) -, o que o leva a observar, então, que a "problemática da resistência é moderna e se articula intimamente à ideia de reação como oposto e simétrica à ação nesse contexto histórico" (ibidem, p. 330).

Se o Estado tem o poder de intervir sobre a cidade demolindo casas para poder abrir novas ruas ou realizar obras de metrô, para recuperar dois exemplos, o que se destaca com a sigla é a forma com que tal poder comparece: como pichação na moradia privada, mancha na parede externa da casa, que não pode, no entanto, ser retirada (limpa?) por ter sido feita pelo Estado. A foto, ao lado da pichação pelo Estado, produz outros efeitos: da força estética da arte em oposição à mancha pelo Estado.

Com as fotos nas paredes das casas tem-se a resistência como reação à ação do Estado. A questão que fica para outra reflexão é quanto à simetria: até que ponto à força do Estado se opõe a outra força - simétrica - da estética da arte?

\section{Referências bibliográficas:}

BARTHES, Roland. 2009. A câmara clara. Lisboa: edições 70.

BIRMAN, Joel. 2006. Arquivos do mal-estar e da resistência, Rio de Janeiro: Civilização Brasileira.

CAMPOS, Andrelino. 2007. Do quilombo à favela: a produção do "espaço criminalizado" no Rio de Janeiro , $2^{\mathrm{a}}$. ed. Rio de Janeiro: Bertrand Brasil.

DAVIS, Mike. 2006. Planeta favela, São Paulo: Boitempo.

\footnotetext{
${ }^{6}$ São fruto de uma intervenção artística ocorrida em maio de 2011, inserida em um Projeto Inside-Out, que tem proposta dar visibilidade a questões sociais no mundo A intervenção não apareceu na grande mídia impressa. As fotos podem ser vistas em sites internacionais e brasileiros. Um deles é: http:www.insideoutproject.net/
} 
DINIZ, André e HORA, Maurício. 2011. Morro da favela, São Paulo: Leya.

ELIA, Luciano. 2010. O inconsciente público e coletivo e a estrutura da experiência psicanalítica. Trabalho apresentado no IV congresso de Psicopatologia Fundamental, organizado pela Associação Universitária de Pesquisa em Psicopatologia Fundamental. Curitiba.

FLUSSER, Vilém. (.2011. Filosofia da caixa preta. São Paulo: Annablume.

HEIDEGGER, Martin. "Construir, habitar, pensar". Tradução por Marcia Sá Cavalcante Schuback. In: <http://www.prourb.fau.ufrj.br/jkos/p2/heidegger_construir,\%20habitar \%20pensar.pdf $>$

HOUAISS, Dicionário eletrônico Houaiss da língua portuguesa. 2003. versão eletrônica.

GINSBURG, Carlo. 1989. Mitos, emblemas, sinais: morfologia e história. São Paulo: Companhia das Letras.

GUELLER, Viviane. 2001. Sem título. Fotografia.

HENRIQUES, Claudio. 2007. Morfologia, Rio de Janeiro: Elsevier.

MARIANI, B. e MEDEIROS, V.. 2011. "MULHER na FAVELA e CONFRONTO POLICIAL: por um arquivo de imagens", In: Mariani, Bethania; Medeiros, Vanise; Silva, Silmara Dela. (org.) Discurso, arquivo e... Rio e Janeiro: 7LETRAS.

MULTITUDES, Inculte Revue, no. 49, été, (2012), pag. 114-131. Revista impressa e em site: www.revuemultitude.net.

ORLANDI, E. 2008. "Violência e Processos de Individualização dos sujeitos na contemporaneidade." In: SARGENTINI, V. e GREGOLIN, M. S. (orgs.) Análise do discurso: heranças, métodos e objetos, Sargentini, São Carlos, Claraluz.

2010. Formas de individuação do sujeito feminino e sociedade contemporânea: o caso da delinqüência. IN: ORLAN̉DI, Eni (org.) Discurso e políticas públicas urbanas; a fabricação do consenso. Campinas, RG Editora.

2004. Cidade dos sentidos, Campinas, SP: Pontes.

PÊCHEUX, Michel. (1988 [1975]) Semântica e discurso. Campinas, Ed. Da UNICAMP.

RISÉRIO, Antonio, A cidade no Brasil, (2012) São Paulo: 34 ed..

SONTAG, Susan. Diante da dor dos outros, (2003) São Paulo: Companhia das Letras.

Sobre a fotografia, (2004) São Paulo: Companhia das letras.

SILVA, Luiz Antonio Machado (2009). "Quarenta anos de sociologia das classe populares urbanas”, in: Carneiro, Sandra de Sá; Sant'Anna, Maria Josefina Gabriel (orgs.), Cidades, olhares, trajetórias, Rio de Janeiro: Garamond, FAPERJ. 
Para citar essa obra:

MARIANI, Bethania; MEDEIROS, Vanise. E quando a pichação é da prefeitura? Pichar, proscrever, dessubjetivizar. RUA [online]. 2013, no. 19. Volume 1 - ISSN 1413-2109

Consultada no Portal Labeurb - Revista do Laboratório de Estudos Urbanos do Núcleo de Desenvolvimento da Criatividade

http://www.labeurb.unicamp.br/rua/

Capa: HORA, Maurício. s./d. Disponível em:

<http://www.cultureisyourweapon.com/2011/06/providencia-inside-out/>

Laboratório de Estudos Urbanos - LABEURB

Núcleo de Desenvolvimento da Criatividade - NUDECRI

Universidade Estadual de Campinas - UNICAMP

http://www.labeurb.unicamp.br/

Endereço:

LABEURB - LABORATÓRIO DE ESTUDOS URBANOS

UNICAMP/COCEN / NUDECRI

CAIXA POSTAL 6166

Campinas/SP - Brasil

CEP 13083-892

Fone/ Fax: (19) 3521-7900

Contato: http://www.labeurb.unicamp.br/contato 